\title{
AN INTELLIGENT AUTOMATIC ATTENDANCE MANAGEMENT SYSTEM FOR STUDENTS USING FACE RECOGNITION
}

\author{
Dr. S Dhanasekaran \\ Associate Professor, Computer Science and Engineering Department \\ Kalasalingam Academy of Research and Education, Krishnankoil, Srivilliputtur, Tamilnadu, India. \\ Santosh S, Vaisak S Nair, Varatha Raman S \\ Bachelor of Technology, Computer Science and Engineering Department \\ Kalasalingam Academy of Research and Education, Krishnankoil, Srivilliputtur, Tamilnadu, India.
}

\begin{abstract}
One of the fastest and foremost emerging and interesting technology is Face Recognition. In this fast-evolving generation, attendance is usually a problem among the school community and so as the business community. one among the foremost efficient solution for this problem is that the Digital Attendance System. Nowadays Computers play a vital role in many fields. Likewise, in this field also, we will make an efficient use of it. This unique scholar's attendance system based on face recognition, is a method to identify and recognizing faces of the student with the help of images captured from a high-quality camera and uploading the attendance of every student automatically, rather than manual attendance uploading process. In our face recognition project, a smart system is going to be ready to capture a frame from a video and process it accurately and predict which of the scholar is present therein class. There are some algorithms and programs to detect the face of an individual, but the concept to be implemented here is Neural Networks. In this we have used a neural network, we will capture the image of class and extract the face image, then pre-process it for a clear face, and will be given to the trained network so the face of the student will be often identified and updated automatically within the database.
\end{abstract}

\section{INTRODUCTION}

Lots of Technical oriented innovations are emerging in our day to day life. This technology makes the globe running efficiently both knowledge-based and also economically. Deep Learning \& Neural Network are some of the interesting domains. These domains permit the machine to the coach itself using some datasets that are provided as input and we are rewarded with certain output during testing based on the applied algorithms by which they were trained. Everybody knows that attendance is one among the foremost considered things in today's world to understand the presence of everyone in any quite organization especially in a class environment and business environment. We will use the advanced technique and best neural network technology with which the system automatically identifies the student and updates the attendance. Not only detects the attendance but also the collected data is maintained fairly and efficiently. Generally, attendance of the students is maintained in two conventional ways, which are,

- Hand/Manual maintenance of student's attendance.

- Digital maintenance of student's attendance.

The process involved in the Manual Attendance System is, an educator especially in a class wants to call the scholars name and perform the manual attendance process. This system is taken into account as a time-consuming process as in schools or colleges sometimes teacher might miss someone or a student may say present for his/her absent friend or perhaps some students leave the class in-between for a few personal or for a few mandatory reasons and even in some cases the teacher may benefit of manual attendance and mark absent for college kids who are disobeying them. So, in these cases manual attendance seems to possess both problems and also advantages. To unravel these issues, we accompany a Digital Attendance System.

A Digital Attendance might be a way to automatically predict the scholar is inside the class or he/she is absent thereto a particular class. This will be easily achieved with the assistance of a face 


\section{International Journal of Engineering Applied Sciences and Technology, 2020 Vol. 5, Issue 2, ISSN No. 2455-2143, Pages 573-582 \\ Published Online June 2020 in IJEAST (http://www.ijeast.com)}

recognition technology. In examination centers also it can be implemented to confirm the presence of the scholar. In future updates it's also possible to acknowledge whether the scholar is sleeping or awake when the staff is in the class busy with him/ her lectures. The scholar's attendance is often predicted by imaging the faces of the scholars through a high-quality camera. This will help the system a lot to analyze each photo frame extracted from the video captured by the camera and update the presence of the students.

\section{LITERATURE REVIEW}

Attendance and Feedback System based on Machine Learning: In [1], Nandhini R, Duraimurugan N, S.P.Chokkalingam et al. (2019) have applied two approaches to the scholar attendance and feedback system's idea of machine learning. The system tracks and keeps monitoring the student performance automatically maintains and updates the student records like attendance and the feedback given by those students as per the guidelines for each staff with whom they are assigned with. Thus, the scholar's attendance is often made ensured that it is updated regularly by identifying the scholar's presence in those class hours. Once identified, marks for the scholar and their presence in those classes will be automatically updated.

Automated Attendance System: [2] The uses various face recognition and detection algorithms, which is employed to recognize the scholar's face when students enter the category, and their proposed system can put attendance by identifying him/her. H. Rathod, Y. Ware, S. Sane, S. Raulo, V. Pakhare, and I. A. Rizvi et al. (2017) have used the Viola-Jones algorithm, which is using SVM for detecting and classifying human faces and uses PCA algorithms for cascade classification and have selection. This technique saves time and helps in monitoring student's presence in comparison to traditional attendees.

\footnotetext{
Student Attendance System Based on Detection of Human Iris: [3] This type of system works as the scholar is identified by asking him/ her to face ahead of the camera to acknowledge the iris of the scholar and thereby identifying the presence of the scholar within the classroom. Some algorithms like conversion of grayscale and more are accustomed to detect iris of a human being. This helps avoid proxy and it effectively works in case of universities for maintaining student's presence in their class, but one among the foremost disadvantage is, it is timeconsuming processes for a scholar or a lecturer to attend until previous member updates his/her attendance.
}

Face Detection based Lecture Attendance System: [4] This journal paper fills our mind with the information, that the detection of the presence of the students by the system is achieved by continuous inspection. Continuous observation helps the system assess and improve their performance. to upload attendance, pictures, and facial images of students within the classroom are taken through a camera. With the recorded video, the system the existence/presence of students in the class for that particular hour.

Automatic Attendance System Based on Deep Learning: In [11] M. Arsenovic, S. Sladojevic, A. Andela and D. Stefanovic et al. (2017) have used deep learning framework in this paper. It proposes an automatic attendance system with two processed steps for college students which supports image processing: first facial detection and second facial recognition. Their method uses a sophisticated facial recognition model to identify students' faces, and at the same time, they have a unique identity structure for accepting and assessing faces. The state-of-theart network is deeper than their proposed face verification network and the performance they achieve is similar. It eventually achieved $98.67 \%$ on LFW and $100 \%$ for the class data he supplied.

CNN approach for vision-based student recognition system: [12,14] There are many ways to implement facial recognition-based presence systems, in different facial recognition techniques, here the author uses a deep learning-based facial recognition method. This method uses $\mathrm{CNN}$ algorithm called embedding to promote the representation in the form of coffee dimensions. And with the help of this embedding the face of the person is found. Many applications such as student attendance, building security, etc. can be developed through this system.

R-CNN Based Attendance Management System by Face Recognition: [13] This journal paper tells that how we can include RCC based system to detect the faces and classify the images of subsets. Exhausting recognition of face-built presence pattern system. This System uses videos technique where a camera is kept in the classroom and which take the live recording and the videos are recorded continuously and faces are detected. These methods and technologies ready to take attendance automatically. This proposes paper may be a technique of accelerating an inclusive class presence scheme by makeover gratitude. This technique applies the Gabor filter method to extract the picture features and RCNN is done for classification of image. 


\section{International Journal of Engineering Applied Sciences and Technology, 2020 Vol. 5, Issue 2, ISSN No. 2455-2143, Pages 573-582 \\ Published Online June 2020 in IJEAST (http://www.ijeast.com)}

\section{EXISTING SYSTEMS}

Recognition system based on Fingerprint: In [5], the system is based on a fingerprint scanner, a fingerprint tech with the capacity of portability must be ready with the scholar's fingerprint already imprinted on it. On the time or after the class, the scholar must imprint his finger on that fine configured tech to attendance of that particular period. M. M. H. Ali, V. H. Mahale, P. Yannawar, and A. T. Gaikwad et al. (2016) address that the disadvantage of this approach is that it can distract students during the lecture. It is also possible that a student may cheat the lecturer by just coming to class and keeps his fingerprint and leave the class before the lecturer comes and again at the end, reappears after the staff left the class to re-keep his finger and gets attendance.

Recognition System based on Radio Frequency Identification: [6] Through this type of system, the student must register with his / her Radio Frequency Identification Card and the ID in the card should be read by the reader for his / her attendance of the day. The system can connect to RS232 and register a presence in the saved database. There may be opportunities for fraud access. T. S. Lim, S. C. Sim and M. M. Mansor et al. (2009) emphasize that some students may use other student IDs to confirm their attendance in the absence of a student, or students will try to take advantage out of it.

Recognition System based on Iris: [7] This system requires the scholar to face ahead of the camera, this permits the camera to scan the scholar's eyes for his iris. This iris should match the info of the scholar's iris stored within the database and update the existence. In this manner we will prevent the standard method of using pen and paper for taking attendance. It will decrease the likelihood of assessments within the classroom and helps to maintain the database. This is a wireless technology, which solves the matter of spontaneous existence and therefore the difficulty of getting an affiliate network. Prashik S. Bhagat, Prof. D. S. Shilwant, Prof. S. P. Kharde, Praful S. Bhagat, Abhijit S. Andure, Prof. Amol A. Shirsath et al. (2015) addressed that the disadvantage of using this is it is too costly to implement and also time-consuming as each student should be ahead of the camera frequently to create his name in the attendance sheet.

Face Based Recognition System: [8] Facial recognition technology is usually familiar with record attendance employing a high-resolution camera, which detects and identifies student's faces and matches faces with student's face that is maintained by the database. Only if the scholar's facial image is connected with the face maintained in the database, the presence of the student will be considered for further calculations. If the facial image that is taken doesn't connect the faces of the scholars within the previously maintained database, then the image will be stored within the database as a fresh entry. In this process, there is a chance that the camera won't capture the image properly or some students might be turned around and missed the camera while it taking the image.

\section{OBJECTIVE OF THE PROPOSED CHAPTER}

This project's objective is to take each student's facial image and train the CNN with it in the system and use the trained CNN for future use. We need to capture the student's face, confirm all the features of the student's face, even the seating position, and identify the student's posture. Once the images are captured, we will use it for training our model. Now, the system will take photos of class in some time interval and it will be sent to the trained model. The model will predict the faces and automatically updates the attendance of the student. The teacher does not have to take attendance in the classroom manually as the attendance database is updated automatically without any manual intervention.

\section{CONTRIBUTION IN THIS CHAPTER}

Our main thought that driven our mind to work with this concept is the difficulties that our college faculties facing during attendance checking time in a class. Normally it is a time-consuming process for faculties to take attendance every period either at the beginning or at the end. This can consume their teaching time and even students may easily cheat the staff by saying present for his/her absent friend. To avoid such things what we, the authors of this project, did is, we decided to develop a program that can record a $2 \mathrm{~s}$ to $5 \mathrm{~s}$ video in regular interval of time (let's say for every 15 mins). Then our program will extract each frame and get the details of the present student and update their attendance in an Excel sheet as per the time table given by the institution.

\section{PROPOSED WORK}

The main processing method and rule of this system is that, for training purposes the images of students are extracted from the frames if the live video. Now during class time classroom image is taken and sent to the system, the trained network predicts the face and student's attendance is given, else the system enters absent for the student in the database. The following are the steps involved in our project.

- Capture Images: The Camera is placed in front of the classroom capture images of class and makes 
sure that the camera doesn't lose its quality of the picture. (Use High-quality camera) The photo of the whole student's community of the class is taken in time interval.

- Detection of Faces: The important and intelligent process where the image which is extracted from each class photo is given as an input (picture) to this smart system. The system will detect face from the class image and will be sent to face crop function.

- Face Cropping: The Faces of every student are cropped from the Captured Images of the category. Faces of the students are enhanced and are ready for face recognition. To achieve this convolution neural network algorithm is used in this project.

- Recognition of Faces: Once the detection phase of this project is over, next starts the recognition phase, where the cleaned-up picture will be sent to our trained model. If present, it will return the present status for that particular student.

- Final Processing: The last and final step of this project involves the easier method of updating the names of the scholar in their database. So that every staff in the community could easily understand and edit. This can be achieved by storing the obtained result in the form of Excel sheets. These excel sheets are accessed by the concerned staff.

\section{PRE-PROCESSING IMAGE FOR EXTRACTING DETAIL FROM FACE}

The pre-processing technique usually enhances and improves the proposed system's performance and also recommended to implement it in every recognition works. As this plays a crucial role in the image recognition system. There are many techniques to improve the details of the captured image. Few pre-processing techniques are going to be applied to the captured image to get more facial features in the image. In which scaling is one among the technique which is an important pre-processing technique that controls the dimensions of the captured image. Reducing the resolution down of a picture increases the processing speed by reducing the system computations process since the number of pixels is reduced in the scaled image. To extract features from facial images, the dimension of the image should be the same.

\section{SCALING OF IMAGES}

Scaling of images is an important task. It should be done very carefully since manipulating it over can cause loss of spatial information from the image. Hence for facial recognition the size of the cropped face should be an equalized one. Once the size is fixed it should not be changed since we are going to use this in training, testing, and working place. Thus, during this proposed approach test images and train images are standardized at size $250 \times 250$ pixels.

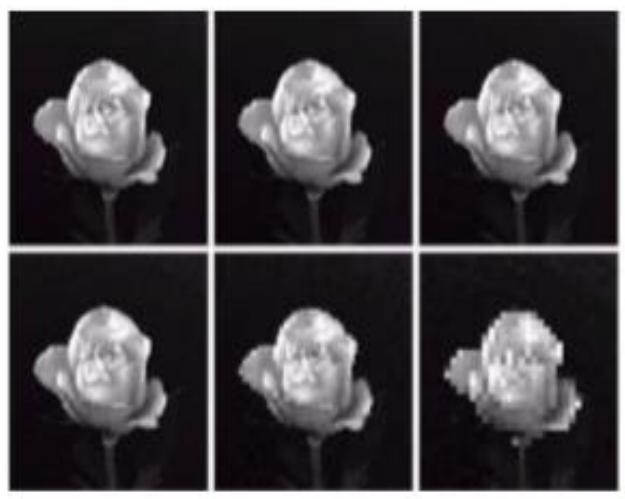

Figure 1: Scaling of image

\section{CONVERSION OF GRAYSCALE}

The image that's captured by the camera is going to be coloured. But the proposed Convolutional Neural Network method can only give better results in greyscale images. So captured images are converted to greyscale. By converting the captured color images to grayscale images, the complexity of the computation is usually reduced resulting in a higher speed of computation.

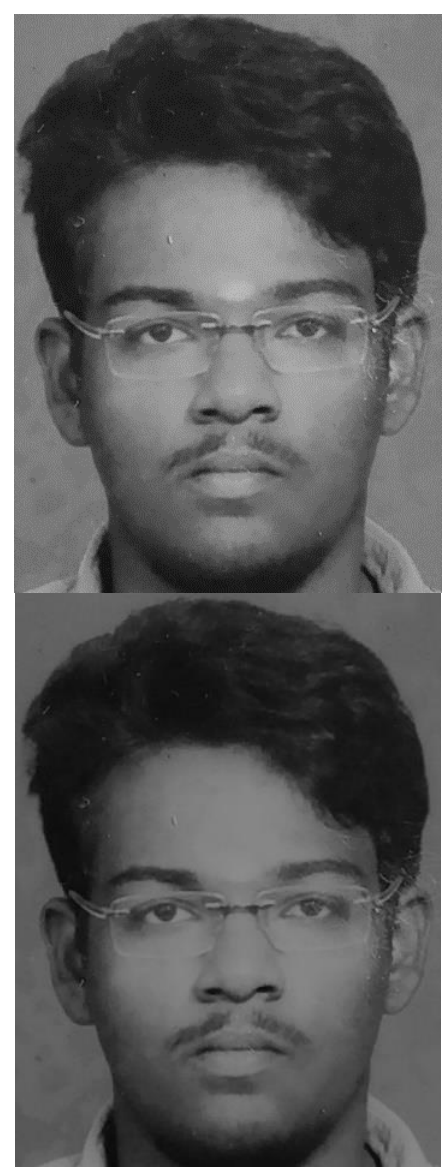

Figure 2: Images After Grayscale Conversion 


\section{CONTRAST LIMITED ADAPTIVE HISTOGRAM EQUALIZATION}

Now the images are processed to improve the contrast level. This can be done by Histogram Equalization (HE). There is another technique called the Contrast Limited Adaptive Histogram Equalization technique (CLAHE) which is an improved version of the Histogram Equalization technique. we first applied the Histogram Equalization technique and compared its results with the Contrast Limited Adaptive Histogram Equalization technique (CLAHE) and found that CLAHE had good results. And we also did some combination of all the technique and results are tabulated as:

Table 1. Table of Observation

\begin{tabular}{|c|c|c|c|}
\hline $\begin{array}{c}\text { Pre- } \\
\text { processing } \\
\text { Technique } \\
\text { Used }\end{array}$ & $\begin{array}{c}\text { Number } \\
\text { of } \\
\text { images } \\
\text { in the } \\
\text { folder }\end{array}$ & $\begin{array}{l}\text { Number } \\
\text { of faces } \\
\text { detected }\end{array}$ & Review \\
\hline Greyscale & 300 & 284 & $\begin{array}{c}\text { Non-face } \\
\text { object was } \\
\text { detected as } \\
\text { face }\end{array}$ \\
\hline $\begin{array}{l}\text { Histogram } \\
\text { Equalization } \\
\text { (HistEq) }\end{array}$ & 300 & 265 & $\begin{array}{c}\text { Contrasted } \\
\text { image and } \\
\text { detailed } \\
\text { image }\end{array}$ \\
\hline $\begin{array}{c}\text { Greyscale + } \\
\text { HistEq }\end{array}$ & 300 & 276 & $\begin{array}{c}\text { Contrasted } \\
\text { image and } \\
\text { detailed } \\
\text { image }\end{array}$ \\
\hline $\begin{array}{l}\text { Greyscale + } \\
\text { Contrast- } \\
\text { Limited } \\
\text { Adaptive } \\
\text { Histogram } \\
\text { Equalization } \\
\text { (CLAHE) }\end{array}$ & 300 & 277 & $\begin{array}{c}\text { Good } \\
\text { contrasted } \\
\text { images } \\
\text { with more } \\
\text { no. of } \\
\text { faces } \\
\text { detected }\end{array}$ \\
\hline $\begin{array}{c}\text { Greyscale + } \\
\text { HistEq + } \\
\text { CLAHE }\end{array}$ & 300 & 274 & $\begin{array}{c}\text { Over } \\
\text { contrasted } \\
\text { image and } \\
\text { Highly } \\
\text { detailed } \\
\text { image }\end{array}$ \\
\hline
\end{tabular}

Results obtained from Pre-Processing Technique:

- RGB To Greyscale

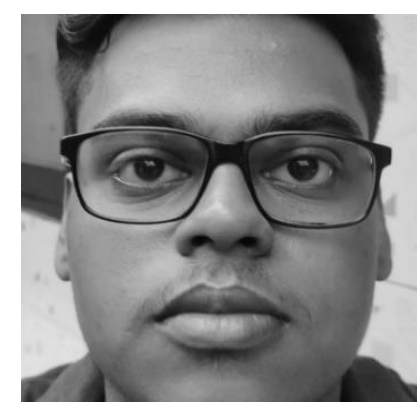

Figure 3: Greyscale image

- Histogram Equalization (HistEq)

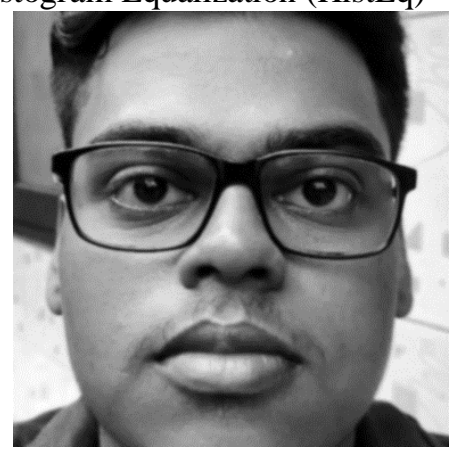

Figure 4: Histogram Equalization image

- Greyscale + HistEq

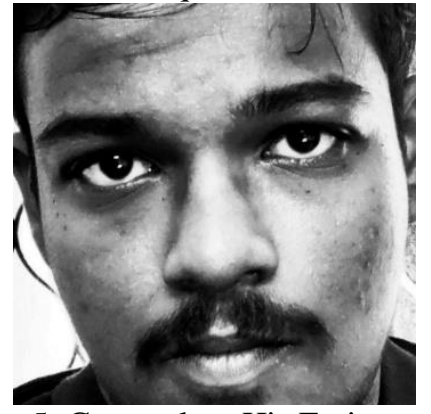

Figure 5: Greyscale + HistEq image

- Greyscale + CLAHE

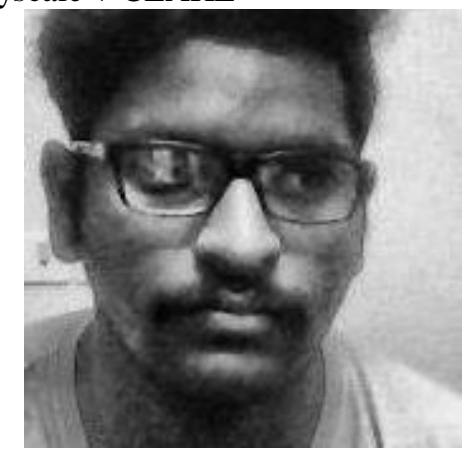

Figure 6: Greyscale + CLAHE image

- Greyscale + HistEq + CLAHE 


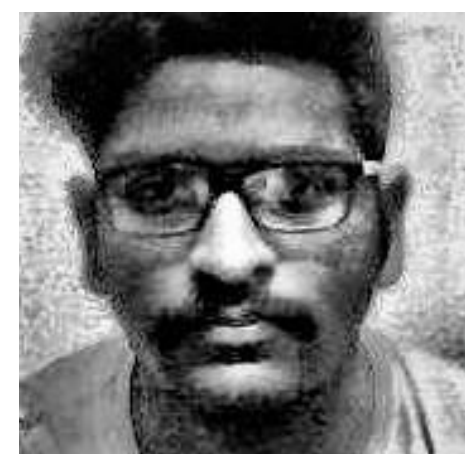

Figure 7: Greyscale + HistEq + CLAHE image

\section{CNN WORKING}

A Convolutional Neural Network (CNN)[10] is a deep neural network. It is a form of a multiple layer perceptron. CNN have been developed for carrying out the necessities quicker when compared to other image processing techniques. Generally, three layers are always present in the Convolutional neural network. In which the first input layer, a hidden layer, and a final output layer that features multiple convolution layers like pooling and normalization layers? The CNN removes the loss of data elements while processing an image and gives us highly efficient outputs that are almost accurate and hence can be used in any places like universities and working organizations, etc., for image recognition. We are using the InceptionResNet-v2 neural network.

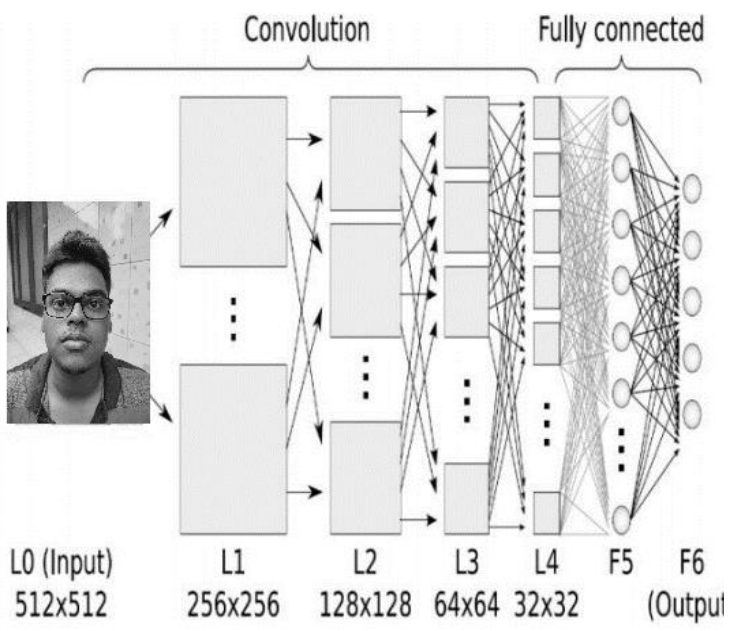

Figure 8: Concept of Convolutional Neural Network
Table 2. InceptionResNet-v2 Vs Other Convolutional Neural Networks.

\begin{tabular}{|c|c|c|c|}
\hline CNN & $\begin{array}{c}\text { Develope } \\
\mathbf{d} \text { by }\end{array}$ & $\begin{array}{l}\text { Accurac } \\
\mathbf{y}\end{array}$ & $\begin{array}{c}\text { erro } \\
\mathbf{r} \\
\text { rate }\end{array}$ \\
\hline AlexNet & $\begin{array}{c}\text { Alex } \\
\text { Krizhevsk } \\
\text { y }\end{array}$ & $73 \%$ & $15 \%$ \\
\hline ZFNet & $\begin{array}{c}\text { Dr. Rob } \\
\text { Fergus }\end{array}$ & $69 \%$ & $14 \%$ \\
\hline GoogLeNet & Google & $80 \%$ & $\begin{array}{c}6.6 \\
\%\end{array}$ \\
\hline VGG Net & $\begin{array}{c}\text { Simonyan } \\
\text { and } \\
\text { Zisserman }\end{array}$ & $78 \%$ & $\begin{array}{c}7.3 \\
\%\end{array}$ \\
\hline ResNet & $\begin{array}{c}\text { Kaiming } \\
\text { He }\end{array}$ & $88 \%$ & $\begin{array}{c}3.6 \\
\%\end{array}$ \\
\hline $\begin{array}{c}\text { InceptionResN } \\
\text { et-v2 }\end{array}$ & Google & $98 \%$ & $3 \%$ \\
\hline
\end{tabular}

We recorded accuracy for different CNN's

\section{Accuracy}

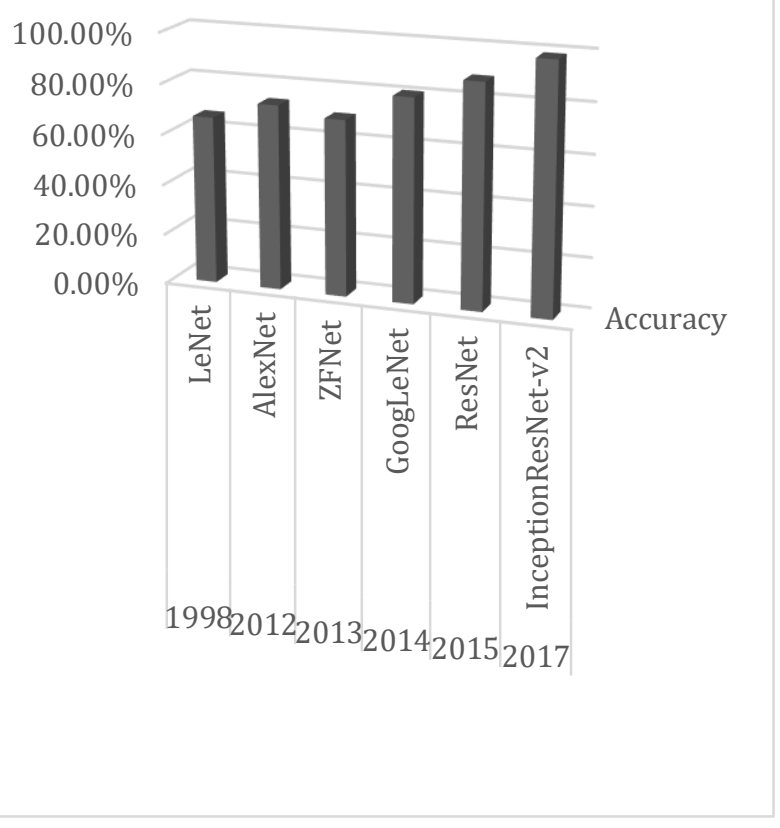

Figure 9: Accuracy

We recorded error rates for different CNN's 
International Journal of Engineering Applied Sciences and Technology, 2020

Vol. 5, Issue 2, ISSN No. 2455-2143, Pages 573-582

Published Online June 2020 in IJEAST (http://www.ijeast.com)

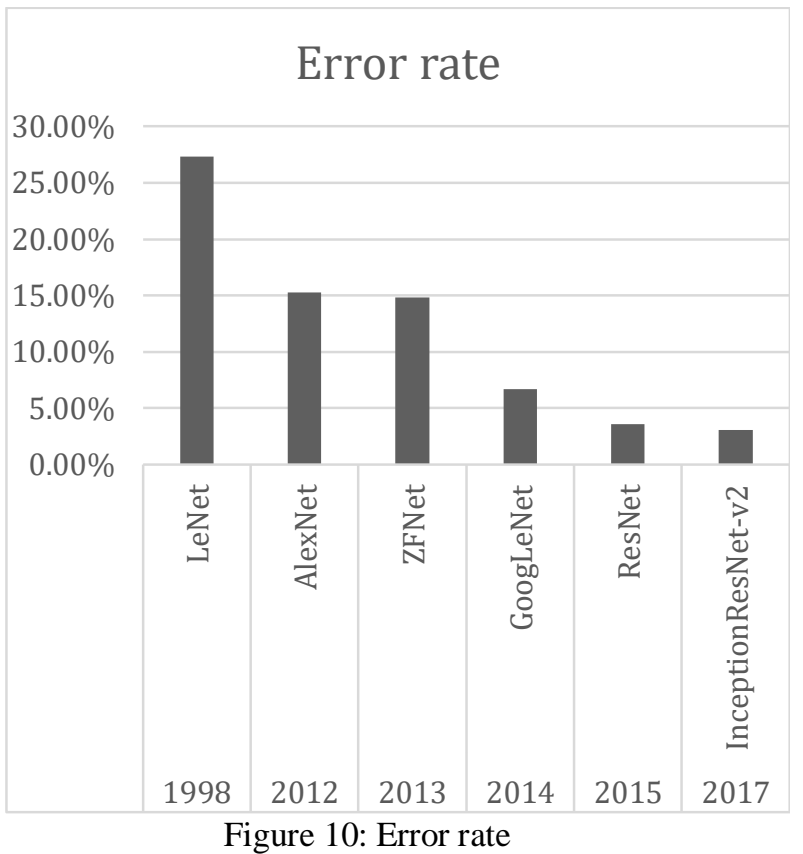

\section{RESULTS AND PERFORMANCE EVALUATION}

- 1.Taking photos of student for training purpose

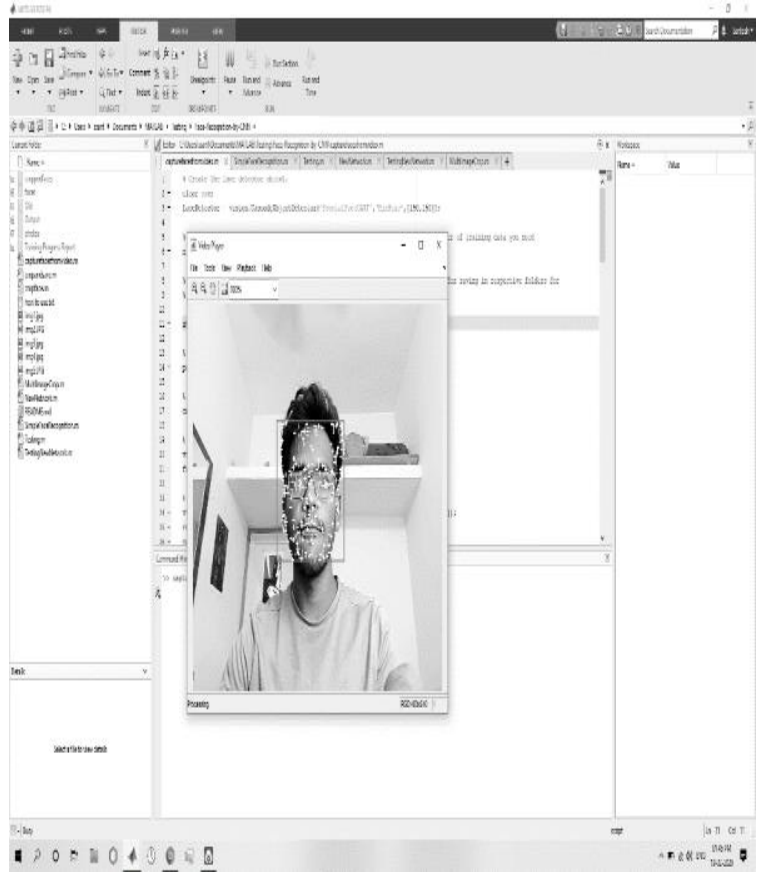

Figure 11: Capturing Picture of Student to train the model

- $\quad$ Training the model with captured photos

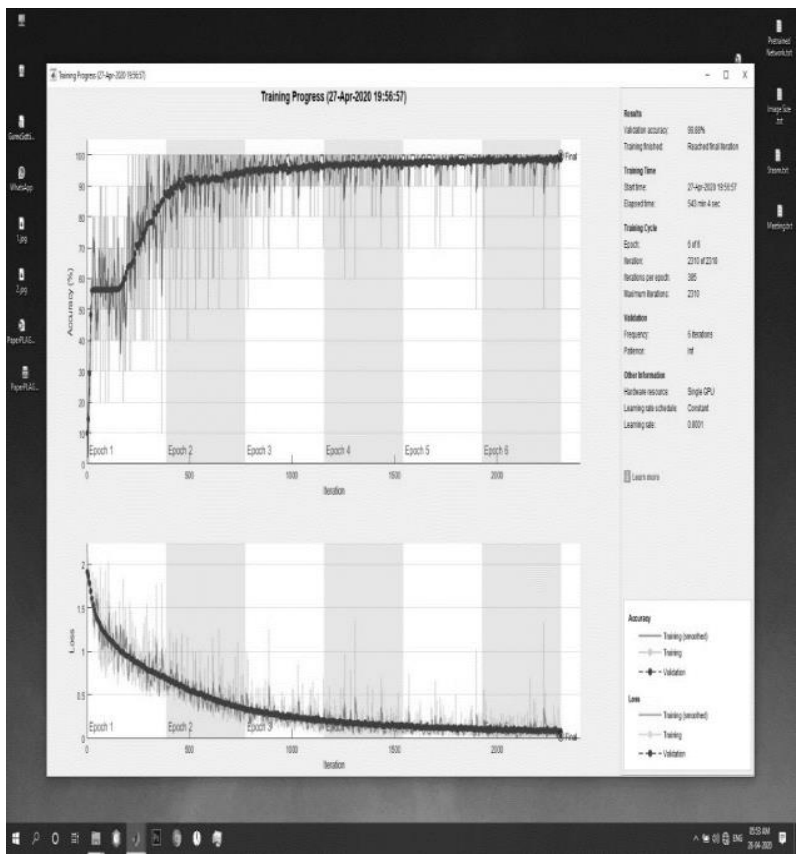

Figure 12: Training the model

- Trained Model Output: Accuracy 0.9988 i.e. $99.88 \%$

Note: Max Accuracy: 1 and Min Accuracy: 0

\begin{tabular}{|c|c|}
\hline \multicolumn{2}{|r|}{ AT-file) } \\
\hline$\boxplus$ Name & Value \\
\hline$\boxplus 1$ & $300 \times 300$ uint 8 \\
\hline 0 YPred & categorical \\
\hline - & $7 \times 1$ struct \\
\hline$\boxplus$ accuracy & 0.9988 \\
\hline (9) augimdsTrain & augmentedlmageSource \\
\hline (1) augimdsValidation & augmentedlmageSource \\
\hline (1) $\mathrm{ds} 1$ & ImageDatastore \\
\hline$\boxplus$ face & 1 \\
\hline ch folder & 'C: Users\ssant \Documents \... \\
\hline$\boxplus \mathrm{i}$ & 7 \\
\hline$\boxplus$ idx & {$[399,386,285,1200]$} \\
\hline [7] imds & ImageDatastore \\
\hline iq imdsTrain & ImageDatastore \\
\hline (91) imdsValidation & ImageDatastore \\
\hline$\boxplus$ img & $300 \times 300$ uint8 \\
\hline (9] inceptionresnetv2_netsave? & DAGNetwork \\
\hline (19) inceptionresnetv2_netsave3 & DAGNetwork \\
\hline
\end{tabular}

Figure 13: Trained model with accuracy 99.88

- $\quad$ Testing the model 
International Journal of Engineering Applied Sciences and Technology, 2020

Vol. 5, Issue 2, ISSN No. 2455-2143, Pages 573-582

Published Online June 2020 in IJEAST (http://www.ijeast.com)

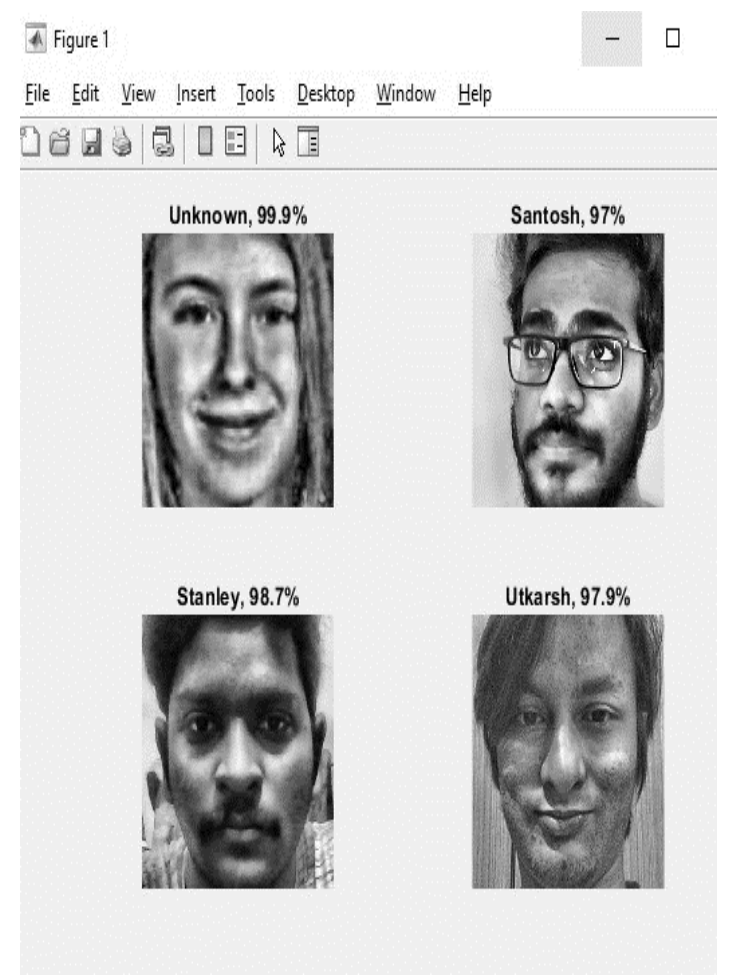

Figure 14: Testing the model

- Now we have to supply a class photo counting many students.

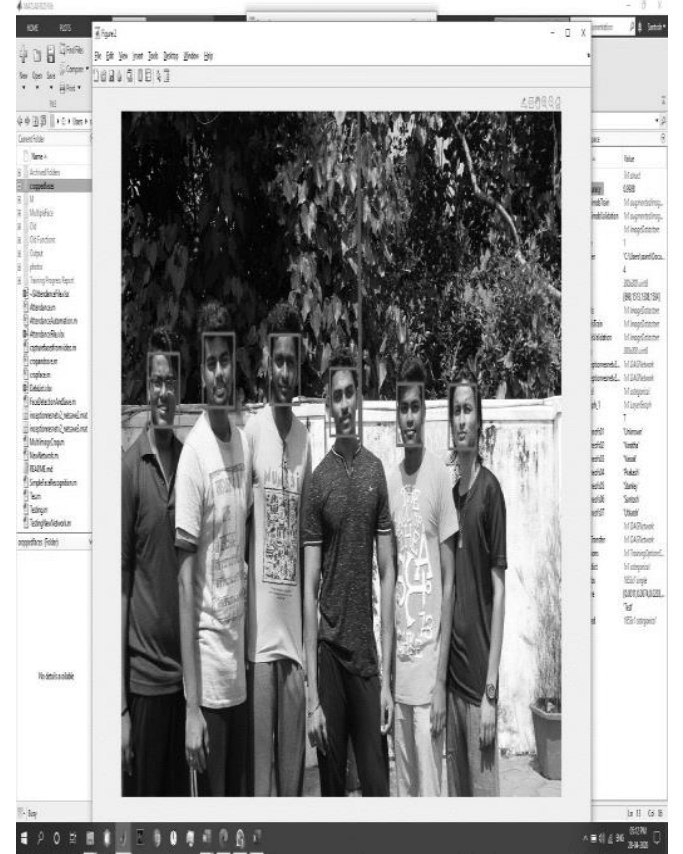

Figure 15: Multiple Face detection

- The program will detect the face applies per processing of image for prediction

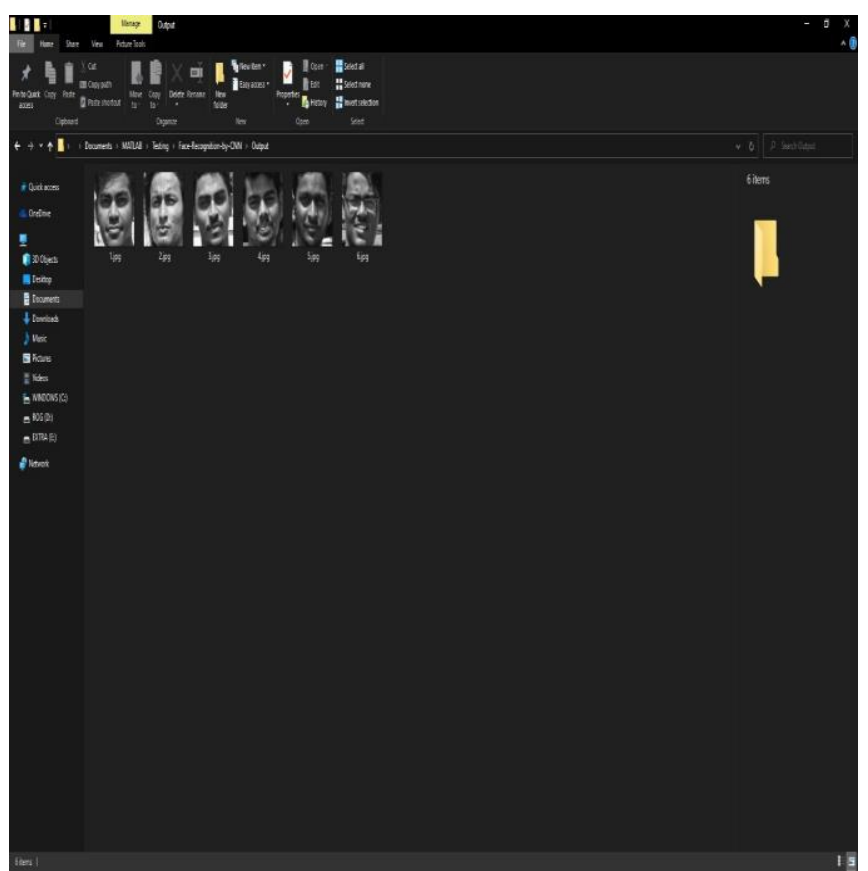

Figure 16: Preprocessing of detected face

- Automatically updating the attendance in the Excel sheet

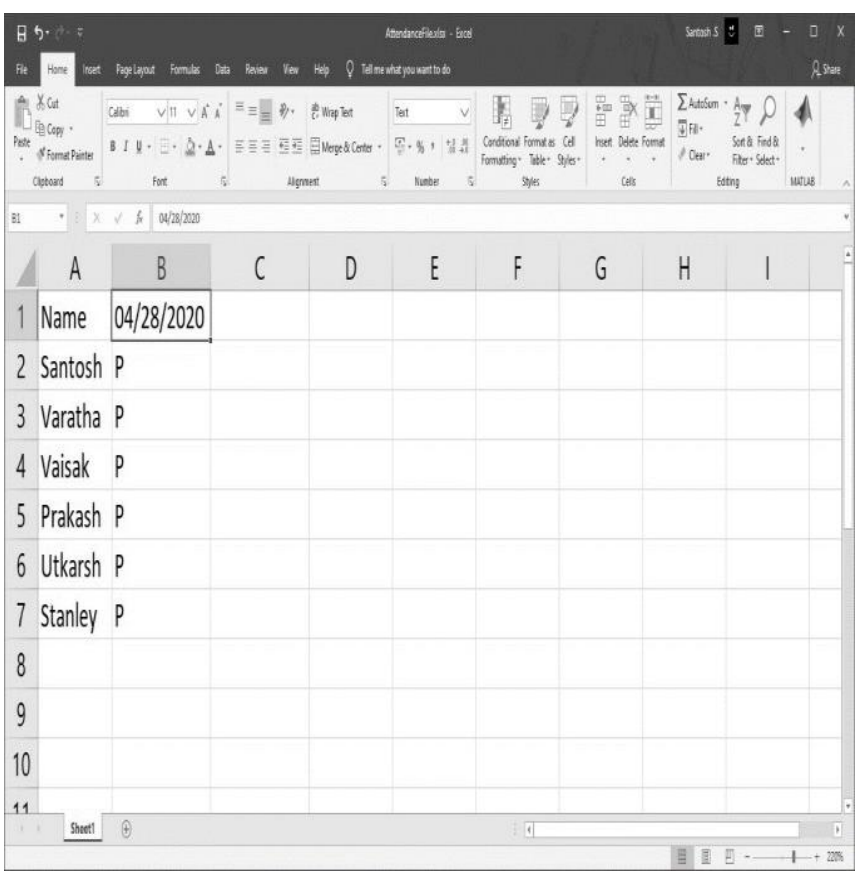

Figure 17: Updated Excel sheet

\section{UPDATES FOR THE FUTURE}

- This will be used in large sectors like an exceedingly seminar hall, where the people are in large numbers.

- Sometimes bad lighting environment in the class may affect the quality of the image which make the training and identify the 


\section{International Journal of Engineering Applied Sciences and Technology, 2020 Vol. 5, Issue 2, ISSN No. 2455-2143, Pages 573-582 \\ Published Online June 2020 in IJEAST (http://www.ijeast.com)}

face of people difficult which ultimately degrades the performance of the system, but this can be improved in future by using good quality of camera. i.e. higher resolution camera or by using some algorithms.

\section{CONCLUSION}

Thus, our project's motivation is to take the image of the scholars to train it with $\mathrm{CNN}$ and save the neural network model. Now Classroom photo which contains students is taken and faces cropped and supplied to the trained network, which classifies or predicts the student and puts attendance for the actual student in the excel sheet, and this excel sheet is used as an attendance record. Thus, this intelligent automatic student attendance management system for university students using face detection methodology helps in automating the work of attendance and increases the speed of execution and its accuracy, from which we finally acquire the accurate real-time presence of the students to satisfy the necessity for updating attendance automatically.

\section{REFERENCES}

[1] Nandhini R, Duraimurugan N, S.P.Chokkalingam (2019), "Face Recognition Based Attendance System" International Journal of Engineering and Advanced Technology (IJEAT) ISSN: 2249 - 8958, Volume-8, Issue-3S.

[2] H. Rathod, Y. Ware, S. Sane, S. Raulo, V. Pakhare, and I. A. Rizvi (2017), "Automated attendance system using machine learning approach," 2017 International Conference on Nascent Technologies in Engineering (ICNTE), Navi Mumbai, (pp. 1-5), DOI: 10.1109/ICNTE.2017.7947889.

[3] Prajakta Lad, Sonali More, Simran Parkhe, Priyanka Nikam, Dipalee Chaudhari, (2017), "Student Attendance System Using Iris Detection", International Journal of Advance Research and Innovative Ideas in Education (IJARIIE) -ISSN(O)2395-4396, Vol-3 Issue-2 2017.

[4] Daljit Kaur Rashi, Zinal Parekh, Shailaja Mohite (2014), "Face Recognition-based on Lecture Attendance System", International Journal of Engineering Research \& Technology (IJERT) ECONET - 2014 (Volume 2 - Issue 04),

[5] M. M. H. Ali, V. H. Mahale, P. Yannawar, and A. T. Gaikwad (2016), "Overview of fingerprint recognition system," 2016 International Conference on Electrical, Electronics, and Optimization Techniques (ICEEOT), Chennai, (pp. 1334-1338), DOI: 10.1109/ICEEOT.2016.7754900.
[6] T. S. Lim, S. C. Sim and M. M. Mansor (2009), "RFID based attendance system," 2009 IEEE Symposium on Industrial Electronics \& Applications, Kuala Lumpur, (pp. 778-782), DOI: 10.1109/ISIEA.2009.5356360.

[7] Prashik S. Bhagat, Prof. D. S. Shilwant, Prof. S. P. Kharde, Praful S. Bhagat, Abhijit S. Andure, Prof. Amol A. Shirsath (2015), "Iris based attendance system”, International Journal of Advanced Research in Computer Engineering \& Technology (IJARCET) Volume 4 Issue 8, August 2015.

[8] S. Sawhney, K. Kacker, S. Jain, S. N. Singh, and R. Garg (2019), "Real-Time Smart Attendance System using Face Recognition Techniques," 2019 9th International Conference on Cloud Computing, Data Science \& Engineering (Confluence), Noida, India, (pp. 522-525), DOI: 10.1109/CONFLUENCE.2019.8776934.

[9] Marko Arsenovic, Srdjan Sladojevic, Andras Andela, Darko Stefanovic (2017) "FaceTime - Deep Learning-Based Face Recognition Attendance System", SISY 2017 • IEEE 15th International Symposium on Intelligent Systems and Informatics • September 14-16, 2017 - Subotica, Serbia

[10] E. Winarno, I. Husni $\mathrm{Al}$ Amin, $\mathrm{H}$. Februariyanti, P. W. Adi, W. Hadikurniawati and M. T. Anwar (2019), "Attendance System Based on Face Recognition System Using CNN-PCA Method and Real-time Camera," 2019 International Seminar on Research of Information Technology and Intelligent Systems (ISRITI), Yogyakarta, Indonesia, (pp. 301-304), DOI: 10.1109/ISRITI48646.2019.9034596.

[11] M. Arsenovic, S. Sladojevic, A. Andela and D. Stefanovic (2017), "FaceTime — Deep learningbased face recognition attendance system," 2017 IEEE 15th International Symposium on Intelligent Systems and Informatics (SISY), Subotica, (pp. 000053-000058), DOI: 10.1109/SISY.2017.8080587.

[12] S. Sawhney, K. Kacker, S. Jain, S. N. Singh, and R. Garg (2019), "Real-Time Smart Attendance System using Face Recognition Techniques," 2019 9th International Conference on Cloud Computing, Data Science \& Engineering (Confluence), Noida, India, (pp. 522-525), DOI: 10.1109/CONFLUENCE.2019.8776934.

[13] R. R. Atallah, A. Kamsin, M. A. Ismail, S. A. Abdelrahman, and S. Zerdoumi (2018), "Face Recognition and Age Estimation Implications of Changes in Facial Features: A Critical Review 
Study," in IEEE Access, vol. 6, (pp. 28290-28304), DOI: 10.1109/ACCESS.2018.2836924.

[14] N. M. Ara, N. S. Simul, and M. S. Islam (2017), "Convolutional neural network approach for visionbased student recognition system," 2017 20th International Conference of Computer and Information Technology (ICCIT), Dhaka, (pp. 1-6), DOI: 10.1109/ICCITECHN.2017.8281789.1 